\title{
Empirical model to predict the operating temperature of the modules of a photovoltaic system
}

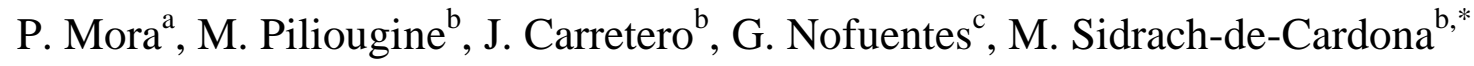 \\ ${ }^{a}$ Departamento de Expresión Gráfica, Diseño y Proyectos, Universidad de Málaga, Doctor Ortiz Ramos s/n, 29071 Málaga, Spain \\ ${ }^{b}$ Departamento de Física Aplicada II, Universidad de Málaga, Boulevard Louis Pasteur 35, 29071 Málaga, Spain \\ ${ }^{c}$ Departamento de Electrónica y Automática, Universidad de Jaén, Campus de las Lagunillas s/n, 23071 Jaén, Spain
}

\begin{abstract}
The aim of this work is the validation of a regression model to forecast the cell temperature of a photovoltaic module under different conditions from those for which it was fitted. In a previous article, a model which uses as inputs the air temperature, the incident irradiation and the wind speed was proposed to forecast the cell temperature. To know if this model could be universally used, the cell temperature of a module of the same technology installed in another location with different weather conditions has been computed using the coefficients estimated previously. From the obtained results, it can be concluded that the model is able to predict the operating temperature of the generator of a power plant and could be applied to this technology at any location regardless of the weather conditions.
\end{abstract}

Keywords: Array operating temperature; empirical model; photovoltaic system

\section{Introduction}

According to data from the International Energy Agency [1], the evolution of the power of photovoltaic origin that has been installed around the world has experienced a significant increment for the last five years. In 2015 the world market has experienced strong growth of a $25 \%$ over the previous year, which is about $50 \mathrm{GW}$ installed annually worldwide, of which $40 \mathrm{GW}$ correspond to installations connected to the grid and only $10 \mathrm{GW}$ to isolated installations. Thus, the total cumulative capacity of photovoltaic origin is left at the end of 2015 at just over $227 \mathrm{GW}$.

The output power delivered by a photovoltaic cell is directly proportional to the irradiance incident on its surface. However, its electric behaviour is also strongly influenced by its temperature, so the hotter the cell temperature is, the less voltage is between its terminals, reducing the energy output. Published models to forecast the energy output of a module need the cell temperature as an input parameter [2]-[8]. Focusing on the scope of photovoltaic modules, the determination of the cell temperature is a very controversial issue. First, as all the cells of the same are not equal, each of them operates at a slightly different temperature. Therefore, the concept of cell temperature of a module is not clearly defined. Despite of this, the module temperature could be considered as the temperature of a representative cell or the mean value of several of them. In addition, as a cell in a module is surrounded by encapsulating materials, a direct measurement of its true value is not possible in general. In most cases, the cell temperature is measured by a sensor attached on the back-surface of the module, supposing that the obtained value is the temperature of the array. In order to forecast the energy output, the array temperature can be expressed in terms of external meteorological conditions (such as air temperature $T_{a}$, irradiance $G$ and wind speed $W_{s}$ ), usually available from weather station close to the photovoltaic plant.

The simplest and most widely model used to estimate the cell temperature is related to the concept known as NOCT [9], that stands for Nominal Operating Cell Temperature. The method supposes that the

\footnotetext{
* Manuscript received October 20, 2016; revised January 20, 2017.

Corresponding author: Tel.: +34951952299; E-mail address: msidrach@uma.es.

doi: 10.12720 /sgce.6.1.40-46
} 
discrepancy between cell temperature and air temperature is directly proportional to the incident irradiance G. Skoplaki and Palyvos [10] present a review of several methods to determine the cell temperature. In a previous work by Mora-Segado et al. [11], some of these models were fitted for a specific location (Málaga, Spain) using measurements taken throughout all the year 2011 for different photovoltaic technologies. In addition, a new model called NOCT-2p, based on the NOCT model, was introduced and validated. The NOCT-2p model outperforms all the other studied models.

However, these previous models are fed using instantaneous measurements and hence the results are very poor, due to the fact that the module never is in a steady state and it presents thermal inertia. Therefore, as it has been done by Mora-Segado et al. [11], it could be very convenient to obtain the respective hourly versions of those models, using the hourly irradiation $H$ (instead of the irradiance) and the hourly mean values of the other variables. The free parameters of the new models should be estimated again using integrated hourly values.

The only lack of that previous work is that universal applicability of the model was not shown, in other words, it is necessary to check if this model, using the parameters fitted for each module technology in Málaga, still behaves relatively well if it is applied to another location with different climate conditions.

The goal of this paper is the application and validation of the NOCT-2p model to predict the operating temperature of a photovoltaic system at any other location. Particularly, the model will be applied to an amorphous silicon (a-Si) generator connected to the grid located in Jaén (Spain), which has a very different climate than Málaga. The values of the required parameters does not need to be estimated again for the new location because the previous coefficients obtained in the year 2011 using data from Málaga (Mediterranean climate) for the a-Si technology are still valid next year for the same technology in Jaén (continental climate). This fact is true despite of the coefficients were estimated with a module not connected to an inverter and in the new location the modules are at their maximum power point.

The rest of this article is structured as follows: Section 2 describes the main elements concerning the measurement acquisition, the description of the NOCT-2p model and the metrics used to quantify the performance of the model. Section 3 presents the results, including a meteorological comparison between the climates of Málaga and Jaén throughout several variables and the validation of the proposed model to compute the operating temperature in Jaén. Finally, in Section 4, the main conclusions of this work are summarised in addition to possible future work.

\section{Method and Materials}

\subsection{Experimental setup}

On the one hand, the previous article by Mora-Segado et al. [11] describes how several flat-plate modules from different photovoltaic technologies (including a-Si) were measured on the roof of the Department of Applied Physics II at the University of Málaga. The modules were on an open-rack fixed structure facing towards south and inclined at $21^{\circ}$. I-V curves were registered every 6 minutes during one natural year (2011) using an experimental system developed in our laboratory and described in detail by Piliougine et al. [12]. In addition to the $I-V$ curve, the main meteorological parameters are recorded, including the irradiance on the module surface (measured by a second-class pyranometer), the air temperature and the wind speed (both of them measured by a weather station), and the cell temperature (using a thermo-resistance sensor attached to the module back surface). Between two consecutive measurements the modules remained in open-circuit state.

On the other hand, there is a photovoltaic system connected to the grid placed at the School of Engineering of the University of Jaén. In this case, the generator is composed off modules from a-Si technology connected to a solar grid-inverter. Therefore, no $I-V$ curves could be recorded because all of modules are operating at their maximum power point. Available data for this experiment are the incident irradiance, the air temperature, the wind speed and the cell temperature of one of the modules of the array.

Based on the database of instantaneous measurements acquired in Jaén, a set of hourly values has been computed, integrating the values of irradiance to obtain the hourly irradiation and averaging the rest of 
measured variables. A set of filters has been applied previously in order to ensure the integrity of the data to be fitted:

- Incident irradiance $G \geq 100 \mathrm{Wm}^{-2}$.

- Discrepancy between cell and air temperature $T_{c}-T_{a} \geq 2.5^{\circ} \mathrm{C}$.

- A minimum of 4 measurements in an hour to perform the integration procedure.

- A maximum of 20 minutes without measurements to compute the integral.

\subsection{Description of the model}

The standard IEC 61215-2 [13] describes a procedure to determine the value of the NOCT parameter for a flat plate module including crystalline silicon devices and thin-film ones. This parameter can be used to estimate the cell temperature $T_{c}$ taking as inputs the air temperature $T_{a}$ and the incident irradiance $G$ (Eq. 1). This is a module-dependent coefficient and is provided in the specification sheet of the module. This parameter is defined as the cell temperature of the module under the following reference conditions: $\mathrm{G}_{r e f}=800 \mathrm{~W} \cdot \mathrm{m}^{-2}, \mathrm{~T}_{a, r e f}=20^{\circ} \mathrm{C}, \mathrm{W}_{s, r e f}=1 \mathrm{~m} \cdot \mathrm{s}^{-1}$ and no load connected (open-circuit state).

$$
T_{c}=T_{a}+G \cdot \frac{\mathrm{NOCT}-\mathrm{T}_{a, r e f}}{\mathrm{G}_{r e f}}
$$

The NOCT-2p model proposed by Mora-Segado et al. [11], fitted and validated over a module of a-Si technology in Málaga, is described by the following expression:

$$
T_{c}=T_{a}+b \cdot G \cdot \frac{\mathrm{NOCT}-\mathrm{T}_{a, r e f}}{\mathrm{G}_{r e f}}+c \cdot\left(W_{S}-\mathrm{W}_{S, r e f}\right)
$$

Eq. (3) provides the hourly variant of the NOCT-2p model. In order to apply this model the values of the parameters $b_{h}$ and $c_{h}$ have had to be estimated from hourly series of records built by integration over the instantaneous measurements:

$$
\bar{T}_{c}=\bar{T}_{a}+b_{h} \cdot H \cdot \frac{\mathrm{NOCT}-\mathrm{T}_{a, r e f}}{\mathrm{H}_{r e f}}+c_{h} \cdot\left(\bar{W}_{S}-\mathrm{W}_{S, r e f}\right)
$$

where $\mathrm{H}_{r e f}=800 \mathrm{~W} \cdot \mathrm{h} \cdot \mathrm{m}^{-2}$ is the irradiation received with a constant irradiance $G=\mathrm{G}_{r e f}$. The fitted values for the parameters for the a-Si technology are reported by Mora-Segado et al. [11] and they are $b_{h}=0.81$ (dimensionless) and $c_{h}=-1.71^{\circ} \mathrm{C} \cdot \mathrm{s} \cdot \mathrm{m}^{-1}$.

\subsection{Metrics to quantify the error}

Different ways to measure the discrepancy between the observed (target) and the predicted (model) values of operating temperature have been considered in this work ( $n$ is the number of samples):

- Temperature mean deviation:

$$
\overline{T D}\left({ }^{\circ} \mathrm{C}\right)=\frac{1}{n} \sum_{i=1}^{n} T D_{i}=\frac{1}{n} \sum_{i=1}^{n}\left(T_{i, \text { model }}-T_{i, \text { target }}\right)
$$

- Standard deviation of the temperature mean deviation (coverage factor $k=1$ ):

$$
S D\left({ }^{\circ} \mathrm{C}\right)=\sqrt{\frac{1}{n} \sum_{i=1}^{n} T D_{i}^{2}}=\sqrt{\frac{1}{n} \sum_{i=1}^{n}\left(T_{i, \text { model }}-T_{i, \text { target }}\right)^{2}}
$$

- Mean absolute error: 
$\operatorname{MAE}\left({ }^{\circ} \mathrm{C}\right)=\frac{1}{n} \sum_{i=1}^{n}\left|T D_{i}\right|$

- Mean absolute percentage error:

$$
\operatorname{MAPE}(\%)=\frac{100}{n} \sum_{i=1}^{n}\left|\frac{T D_{i}}{T_{i, \text { target }}}\right|
$$

- Coefficient of determination (adjusted):

$$
R^{2}(\%)=100 \cdot\left(1-\frac{n-1}{n-p} \frac{\sum_{i=1}^{n}\left(T_{i, \text { model }}-T_{i, \text { target }}\right)^{2}}{\sum_{i=1}^{n}\left(T_{i, \text { target }}-\bar{T}_{\text {target }}\right)^{2}}\right)
$$

where $p$ is the number of parameters to determine (in this case $p=2$ ).

\section{Results}

\subsection{Comparative study of the climates of both locations}

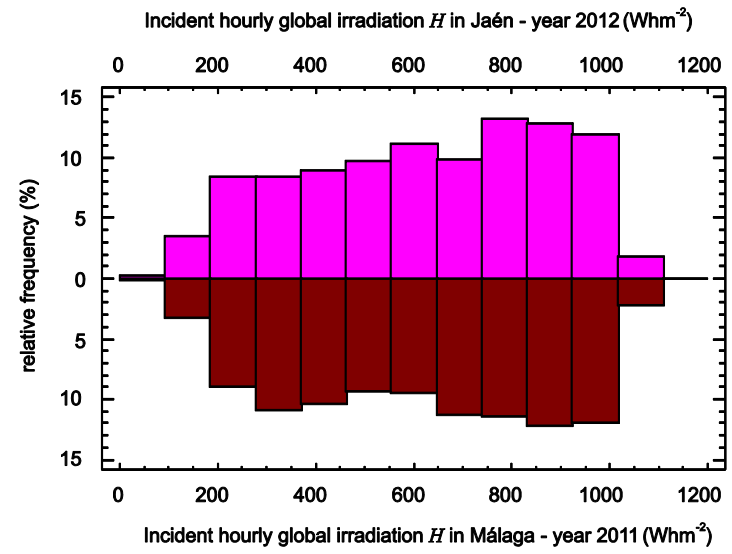

Fig. 1. Histograms of the incident hourly irradiation for Málaga and Jaén.

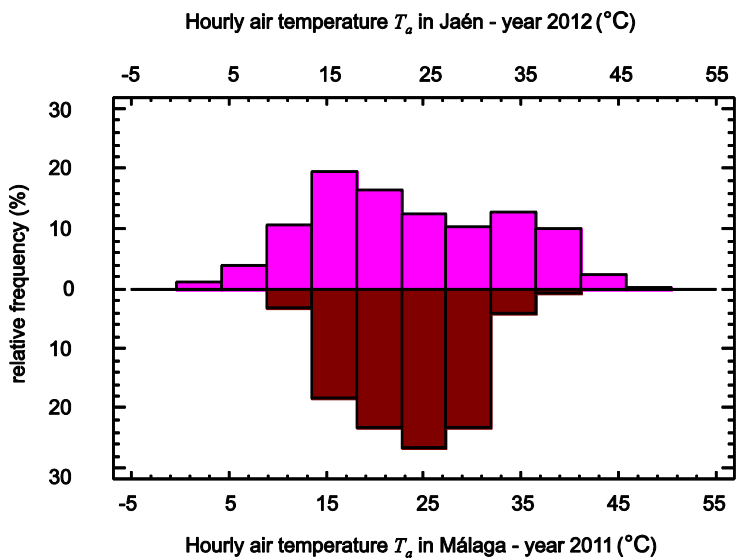

Fig. 2. Histograms of the hourly air temperature for Málaga and Jaén. 


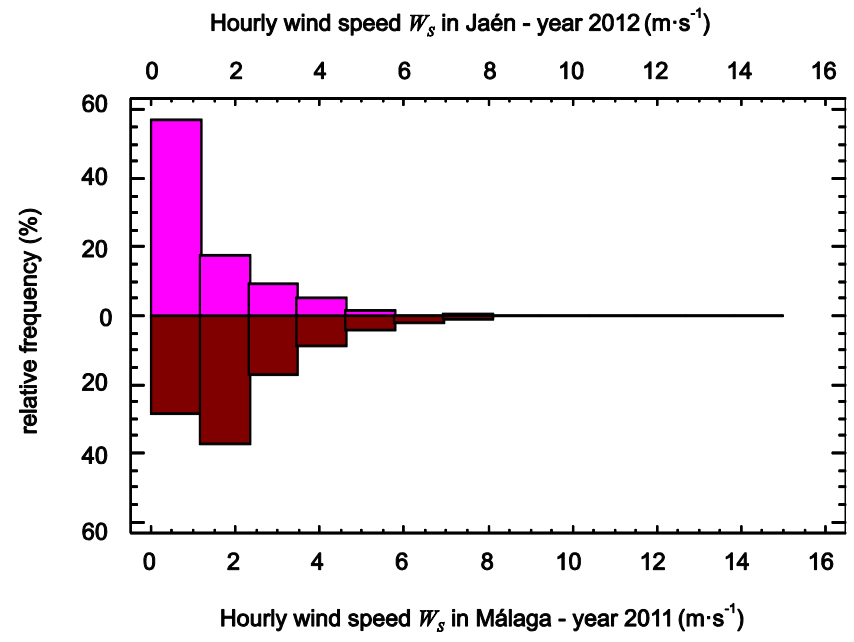

Fig. 3. Histograms of the hourly wind speed for Málaga and Jaén.

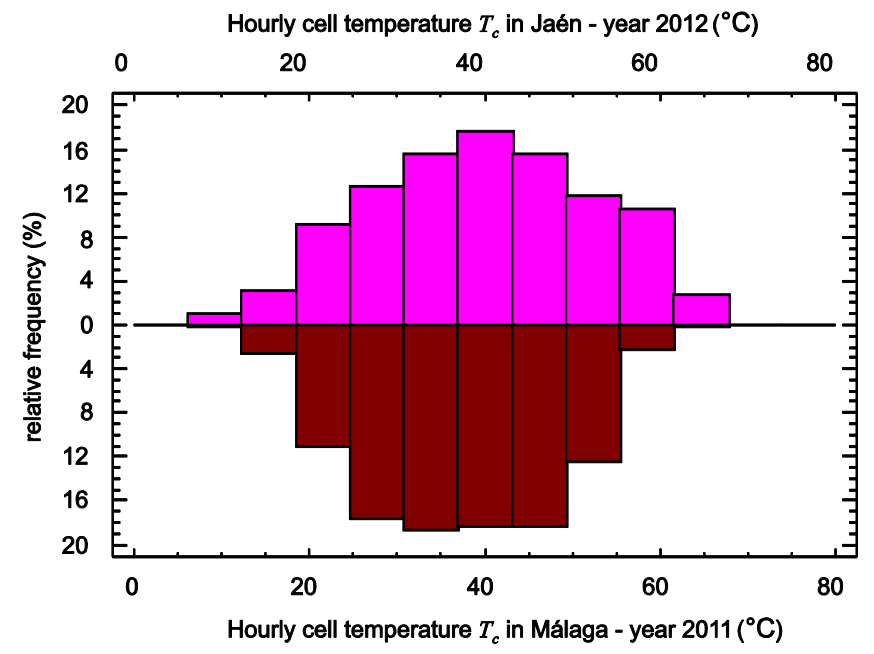

Fig. 4. Histograms of the module temperature for Málaga and Jaén.

The main objective of this research is to check if the NOCT-2p model fitted with the measurements acquired in Málaga can be applied directly to another location with different weather conditions than those in Málaga. For that reason, a statistical analysis of the meteorological variables from Málaga (year 2011) and from Jaén (year 2012) has been performed.

Fig. 1 to Fig. 4 show the histograms of the hourly irradiation, the hourly air temperature, the hourly wind speed and the hourly module temperature in Málaga and Jaén. As can be seen, the distributions of these variables are very different for both locations. The Kolmogorov-Smirnov test was applied to each pair of variables to demonstrate that both of them do not have the same distribution. Therefore, there is a statistically significant difference between the hourly irradiation in Málaga and in Jaén with a confidence level of $95 \%$. This fact also happens to the air temperature, the wind speed and the module temperature module in both cities.

\subsection{Study of the performance of the proposed method at the new location}

Using the values of the parameters provided in Section 2.2, and the hourly NOCT-2p model taking as inputs the database of hourly values from measurements registered in Jaén, the operating temperature of 
the photovoltaic generator has been estimated. Referring this series of values as $T_{\text {model }}$ and the true values as $T_{\text {target }}$, the metrics listed in Section 2.3 have been computed. Table 1 shows the results obtained for each metric.

Table 1. Results of the different metrics over the hourly values of $T_{\text {model }}-T_{\text {target }}$ from measurements of Jaén

\begin{tabular}{cccccc}
\hline Model & $\overline{T D}\left({ }^{\circ} \mathrm{C}\right)$ & $S T D\left({ }^{\circ} \mathrm{C}\right)$ & $\operatorname{MAE}\left({ }^{\circ} \mathrm{C}\right)$ & $\operatorname{MAPE}(\%)$ & $R^{2}(\%)$ \\
\hline NOCT-2p & $! 0.70$ & 2.7 & 1.6 & 4.2 & 96.4 \\
\hline
\end{tabular}

As can be seen, the NOCT-2p model underestimates the operating temperature with a systematic error of $0.7^{\circ} \mathrm{C}$. Piliougine et al. [12] state that the expanded uncertainty (with a confidence level of 95\%) associated to the measurement of the temperature with the thermo-resistance used in experimental system is $1.5{ }^{\circ} \mathrm{C}$ for a measured value of $50{ }^{\circ} \mathrm{C}$. Consequently, the obtained deviation is inside the measurement uncertainty.

Fig. 5 shows the hourly values of $T_{\text {target }}$ versus their corresponding values of $T_{\text {model }}$. As can be seen, the cloud of points is very close to the identity function (high value of $R^{2}$ ), that means a very accurate and precise prediction of the operating temperature (low values of $\overline{T D}, S D, M A E$ and $M A P E$ ).

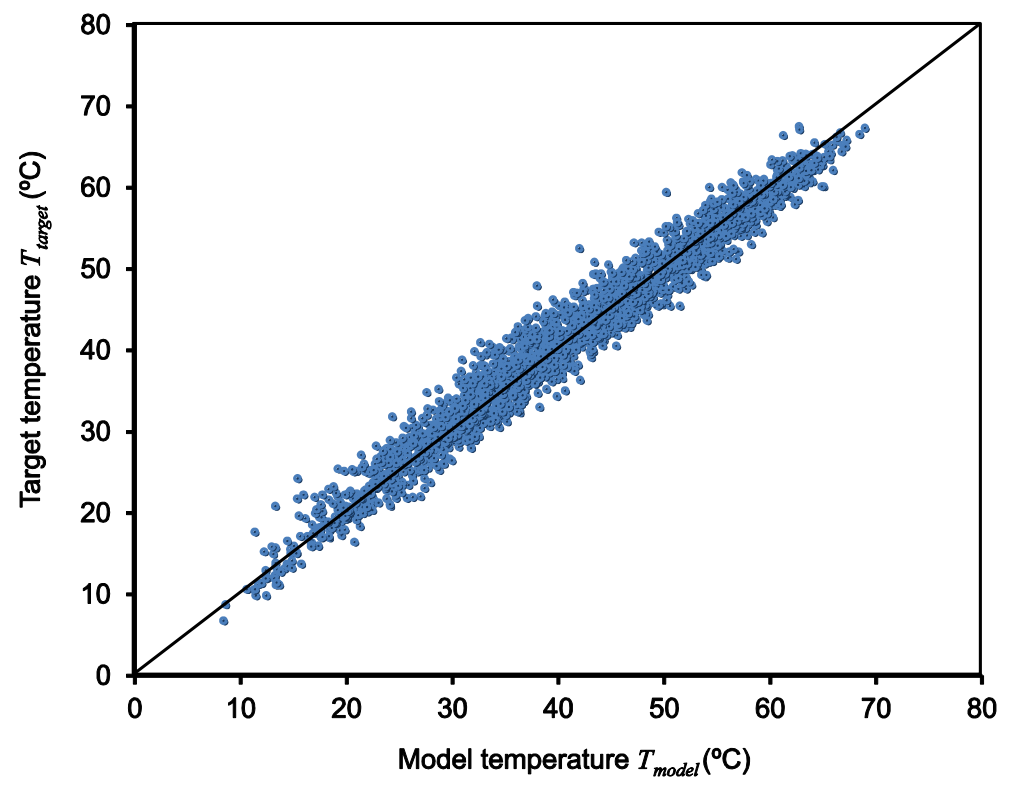

Fig. 5. Set of points resulting by the comparison of model and target operating temperature.

\section{Conclusion and Future Work}

A methodology to estimate the operating temperature of a photovoltaic generator has been presented and validated. In a previous work, a new hourly model referred as NOCT-2p was presented as a tool to determine the hourly cell temperature using as inputs the irradiation, the mean air temperature and wind speed. Its two adjustable parameters were estimated for modules of different photovoltaic technologies by means of a regression procedure using a set of measurements acquired during the year 2011 at Málaga. In this work, it has been tried to test that model to obtain the operating temperature of an a-Si photovoltaic generator connected to a solar inverter installed at Jaén under very different meteorological conditions. Without repeating again the regression procedure, the same values of the parameters fitted previously for the a-Si module (using data from the year 2011 in Málaga) have been used directly to forecast the module temperature in Jaén, using as inputs records from 2012. From the results, it can be stated that the obtained error at the new location is inside the uncertainty of the equipment used to measure the module 
temperature. This fact is true although the parameters were determined in Málaga for a single module without any load and afterwards the same parameters have been used over modules working at their maximum power point and under very different climate.

As the NOCT-2p model was not only fitted for an a-Si module, but also for other three modules of different technologies, next step will be the validation of the parameters obtained for those technologies in other locations. In addition, it could be studied how to combine this model with an energy prediction method to forecast the power output of a photovoltaic solar plant using only meteorological data.

\section{Acknowledgement}

This work was carried out with the financial support of the "Junta de Andalucía" (grant No. P11RNM-7115).

\section{References}

[1] IEA International Energy Agency. 2015 Snapshot of Global Photovoltaic Markets. PVPS Photovoltaic Power Systems Programme. Report IEA PVPS T1-29:2016.

[2] Araújo GL, Sánchez E. Analytical expressions for the determination of the maximum power point and the fill factor of a solar cell. Solar Cells, 1982; 5(4):377-386.

[3] Osterwald CR. Translation of device performance measurements to reference conditions. Solar Cells, 1986; 18(3-4):269-279.

[4] King DL. Photovoltaic module and array performance characterization methods for all system operating conditions. In: Proc. of AIP Conference Proceedings, 1997; 394(1):347-368.

[5] Cañete C, Carretero J, Sidrach-de-Cardona M. Energy performance of different photovoltaic module technologies under outdoor conditions. Energy, 2014; 65:295-302.

[6] Sidrach-de-Cardona M, Carretero J, Mora-Segado P, Cañete C, Piliougine M. Hourly models to estimate the energy produced by photovoltaic modules of different technologies. In: Proc. of 31st European Photovoltaic Solar Energy Conference and Exhibition, 2015: 2057-2060.

[7] IEC 60891. Procedures for temperature and irradiance corrections to measure $I-V$ characteristics of crystalline silicon photovoltaic devices. 2nd ed. Geneva: IEC International Electrotechnical Commission (2009).

[8] Piliougine M, Eizondo D, Mora-López L, Sidrach-de-Cardona, M. Modelling photovoltaic modules with neural networks using angle of incidence and clearness index. Progress in Photovoltaics: Research and Applications 2015; 23(4):513-523.

[9] Castañer L, Bermejo S, Markvart T, Fragaki K, Energy production by a PV array. Chapter IIIa-1 in Practical Handbook of Photovoltaics. Fundamentals and Applications. Markvart T, Castañer L, editors. Elsevier; 2003:517-529.

[10] Skoplaki E, Pavylos JA. Operating temperature of photovoltaic modules: A survey of pertinent correlations. Renewable Energy 2009; 34(1):23-29.

[11] Mora-Segado P, Carretero J, Sidrach-de-Cardona, M. Models to predict the operating temperature of different photovoltaic modules in outdoor conditions. Progress in Photovoltaics: Research and Applications 2015; 23(10):1267-1282.

[12] Piliougine M, Carretero J, Mora-López L, Sidrach-de-Cardona M. Experimental system for current-voltage curve measurement of photovoltaic modules under outdoor conditions. Progress in Photovoltaics: Research and Applications, 2011; 19(5):591-602.

[13] IEC 61215-2. Terrestrial photovoltaic (PV) modules - Design qualification and type approval - Part 2: Test procedures. Geneva: IEC International Electrotechnical Commission. (2016). 